\title{
The effects of preparation period exercises on the hematological parameters of the taekwondo athletes
}

\author{
Boyalı E. ${ }^{1 \mathrm{ABDE}}$, Sevindi T. ${ }^{2 \mathrm{ACD}}$, Yüksel M.F. ${ }^{3 \mathrm{ABDE}}$, Demir H. ${ }^{1 \mathrm{ABCDE}}$ \\ ${ }^{1}$ Faculty of Sports Science, Selçuk University, Turkey \\ ${ }^{2}$ Faculty of Sports Science, Aksaray University, Turkey \\ ${ }^{3}$ Faculty of Education, Necmettin Erbakan University, Turkey
}

Authors' Contribution: A - Study design; B - Data collection; C - Statistical analysis; D - Manuscript Preparation; E - Funds Collection.

\begin{abstract}
Purpose: $\quad$ This study aimed at examining the effects of preparation period exercises, which were applied for eight weeks to elite level taekwondo athletes, on the hematological parameters.

Material: $\quad$ Totally 21 athletes with international degrees from the university taekwondo team participated in this study, 12 of whom were female (Mean age: 20.3 - Mean exercise age: 8.8 ) and 9 of whom were male athletes (Mean age: 20.3 - Mean exercise age: 9.5). The participants attended an 8-week exercise program for 5 days a week, which included basic motoric features and technical and tactical development. $4 \mathrm{cc}$ blood samples were taken from the right antecubital vein before and after the preparation period exercises. On the blood samples, WBC, GRAN, GRAN \%, LYM, LYM \%, MID and MID \% values were examined among leukocyte sub-groups; RBC, HGB, $\mathrm{HCT}, \mathrm{MCV}, \mathrm{MCH}, \mathrm{MCHC}$ and RDWC values were examined among the erythrocyte sub-groups, and PLT, MPV, PCT and PDW values were examined among thrombocyte sub-groups.

Results: $\quad$ At the end of the study, we determined that there was a statistically significant increase in the MCHC values of both the male and the female taekwondo athletes. Moreover, it was determined that there were statistically significant decreases in the HCT, MCV, MCH, MPV and PCT values of the female taekwondo athletes, and in the MCV, MPV and PCT values of the male taekwondo athletes.

Conclusions: As a conclusion, we can state that the 8-week exercises applied during the preparation period affected the hematological parameters of the male and female taekwondo athletes to an extent, however, this effect was limited and it did not cause an important change.

Keywords: Taekwondo, training, university students, leucocyte, erythrocyte, thrombocyte.
\end{abstract}

\section{Introduction}

The data revealed by the studies conducted on athletes, both enables a better understanding of the sport and the sport physiology and it helps interpret the changes occurring in the bodies of people, who are actively doing sports [1]. The effect of exercise on hematological parameters has been a research field for a long time. In many studies, the interrelation of factors determining the performance and physical / physiological characteristics of athletes of the elite level has been established [2-5].

It was reported that the acute exercise has an important effect on the rheological characteristics of the blood [6] and that there was an increase in the erythrocyte hardness and in the plasma viscosity after the acute exercise, while there was a decrease in the sedimentation speed [7]. It is known that both acute and chronic exercises cause various hematological changes in human body. It was determined that the exercise-based hematological changes depended on the type, intensity, and duration of the exercise. Additionally, various factors such as education level, gender, age, environmental conditions, and the nutrition of the subjects have an important role, as well [8].

In the accessible literature findings, we observed differences concerning the effects of exercise on hematological parameters. There are studies reporting that, in the athletes, who attend both acute [9] and chronic intense exercises [2], the hemoglobin [10] and hematocrit values decrease and this case is called as the athlete anemia [9]. Additionally, there are also research studies stating that, when the values before and after the acute sub-maximal exercise are compared, the acute submaximal exercise significantly increases erythrocyte, leukocyte [11], and thrombocyte count, hematocrit and hemoglobin levels [12]; and the researchers determined that these increases depended on plasma losses caused by this exercise [13]. Moreover, it is reported that a short-term exercise until fatigue increases the leukocyte count and this situation cannot be explained by the hemoconcentration mechanism alone. Therefore, the researchers stated that it can be related with metabolic changes such as ischemia developed during the exercise and increased muscle activity. In addition, they claimed that it can cause larger capillary swelling and leukocyte adhesion incidence in the venules [14].

With reference to the possible changes in the hematological parameters based on the type, intensity, and duration of the exercise, we thought that it is important to determine the possible effects of preparation-period exercises on the hematological parameters of elite level taekwondo athletes, which led us to conduct his project. Therefore, the purpose of this study is to examine the effects of preparation-period exercises, which were applied for 8 weeks to elite level taekwondo athletes, on the hematological parameters. 


\section{Materials and Methods}

Participants.

The subjects of this research were chosen among the volunteer athletes. We conducted the research on 21 elite level taekwondo athletes (9 males and 12 females) from the Selçuk University Taekwondo Team, who regularly continued exercises and participated in tournaments. Additionally, in order to compose the elite level athlete group, we determined inclusion criteria. According to these criteria, the athletes to be included in the study must have a 5-year exercise background, must be participated in national and international level competitions, and must have continued exercises for 4 days and over in a week. Moreover, based on the inclusion criteria the participants must be between 17-25 years old, they must have willingness to participate in the study, and additionally no smoking, no use of notorious or mood enhancing supplements, physical and mental health, and no diseases to be detected in the specimens' medical history. Exclusion criteria were first, non-compliance with the training protocol, and second, inability to collect the information sought by the researchers. All the volunteers participating in the research signed the informed consent (volunteer) form and filled personal information form.

\section{Research Design.}

The research method was semi-experimental. It was conducted in accordance with the Declaration of Helsinki, and the protocol was approved by the Necmettin Erbakan University, Meram Medical Faculty, Ethics Committee of non-Pharmaceuticals and non-Medical Device Researches with the decision dated 27/04/2018 and numbered 2018/67.

Before starting the research, we made interviews with the authorities, trainers, and athletes of the team, who were planned to be included into the study as the research group (Selçuk University Taekwondo Team). The athletes participated in an 8-week preparation period exercise before the Interuniversity Taekwondo Turkey Championship that was organized by the Turkey University Sports Federation. All of the measurements and tests of the taekwondo athletes composing the experiment group were carried out in Konya Selçuk University Sports Hall. The preparation period exercises were conducted during June and July of 2018. The physical feature measurements of the athletes were conducted one day before the exercise period began. We organized another meeting with the athletes just before the test, and gave information about the objective and importance of the study. Necessary equipment and test mechanisms for the test and measurements were prepared in the sports hall that hosted the test. Tests were conducted and measurements were taken one day before and after the preparation period exercise. We informed the athletes that they should not take medicine and alcohol the day before and in the same day of blood sample taking activity. While taking the blood sample, the athlete was positioned in a sitting posture on a chair. $4 \mathrm{cc}$ blood samples were taken from the right antecubital vein into the hemogram tubes with K3 Edta by the specialist nurse. After the blood samples were transferred to the laboratory under proper storage conditions without being centrifuged, they were analyzed in the Cell-Dyn 1800 (Abbott Diagnostics, Abbott Park, IL, USA) hemogram device. Among the hematological parameters;

- $\quad$ WBC, GRAN, GRAN \%, LYM, LYM \%, MID and MID \% values from the leukocyte sub-groups were analyzed,

- $\quad \mathrm{RBC}, \mathrm{HGB}, \mathrm{HCT}, \mathrm{MCV}, \mathrm{MCH}, \mathrm{MCHC}$ and

RDWC values from the erythrocyte sub-groups were analyzed,

- 3- PLT, MPV, PCT and PDW values from the thrombocyte sub-groups were analyzed.

The exercises of the taekwondo athletes during the preparation period were conducted according to the content described below.

Besides the warm-up and cooling exercises in each unit of exercise period, the athletes conducted;

- Single and combined technical practices on the

glove (with all the techniques used in the competitions),

- Paired tactical practices on the safeguard,

- Exercise competition (the athletes participated in the competition with the "pull system" method) (sparring),

The practices were conducted in the unit exercise period, and the duration of the exercise was limited to 90 minutes. The level of the competition was revised based on the exercise principles and according to the adaptation status of the athletes.

Statistical Analysis.

SPSS 24.0 (IBM Corp., Armonk, NY, USA) program was used in the analysis of the data obtained in the study, and minimum, maximum, arithmetic mean, and standard deviation values were determined. Since the number of the participants in the research was lower than 30, the differences between the tests applied before and after the exercise were determined via "Wilcoxon Signed Rank Test". Significance level was admitted as $p<0.05$.

\section{Results}

Table 2 shows the age, height, body weight and BMI average values of athletes participating in the study.

The Wilcoxon Signed Rank Test analysis was applied here to determine whether there was significant difference between the pre-test and post-test mean values of the male taekwondo athletes. When Table 3 was examined, according to the mentioned test, it was determined that there were statistically significant differences in the MCV $(\mathrm{z}=-2,675), \operatorname{MCHC}(\mathrm{z}=-2,549), \operatorname{MPV}(\mathrm{z}=-2,092)$ and PCT $(\mathrm{z}=-2,075)$ parameters $(p<0.05)$. However, there was statistically no significant difference $(p>0.05)$ for the other parameters.

The Wilcoxon Signed Rank Test analysis was applied here to determine whether there was significant difference between the pre-test and post-test mean values of the female taekwondo athletes. When Table 4 was examined, according to the mentioned test, it was determined that there were statistically significant differences in the HCT $(\mathrm{z}=-2,943), \mathrm{MCV}(\mathrm{z}=-2,981), \mathrm{MCH}(\mathrm{z}=-2,119), \mathrm{MCHC}$ 
Table 1. Exercise program of the athletes conducted in the preparation period

\begin{tabular}{|c|c|c|c|c|c|c|c|c|c|c|c|c|}
\hline 1 & \multicolumn{3}{|l|}{ PERIODS } & \multicolumn{9}{|c|}{ PREPARATION STAGE } \\
\hline 2 & \multicolumn{3}{|c|}{ MONTHS } & \multicolumn{4}{|c|}{ JUNE } & \multicolumn{4}{|c|}{ JULY } & \\
\hline 3 & \multicolumn{3}{|l|}{ WEEKS } & 1 & 2 & 3 & 4 & 5 & 6 & 7 & 8 & \\
\hline 4 & \multicolumn{3}{|c|}{ PERFORMANCE TESTS } & $\mathrm{T}$ & & & & & & & $\mathrm{T}$ & อ \\
\hline \multirow{6}{*}{5} & \multirow{7}{*}{  } & \multicolumn{2}{|l|}{100} & & & & & & & & & \\
\hline & & \multicolumn{2}{|l|}{90} & & & & & & & & & \\
\hline & & \multicolumn{2}{|l|}{80} & & & & & & & & & \\
\hline & & \multicolumn{2}{|l|}{70} & & & & & & & & & 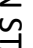 \\
\hline & & \multicolumn{2}{|l|}{60} & & & & & & & & & \\
\hline & & \multicolumn{2}{|l|}{50} & & & & & & & & & \\
\hline \multirow{7}{*}{6} & & \multicolumn{2}{|l|}{ MONDAY } & 1 & 1 & 1 & 1 & 1 & 1 & 1 & 1 & \\
\hline & \multirow{6}{*}{ 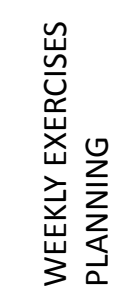 } & \multicolumn{2}{|l|}{ TUESDAY } & 1 & 1 & 1 & 1 & 1 & 1 & 1 & 1 & \\
\hline & & \multicolumn{2}{|l|}{ WEDNESDAY } & $\mathrm{R}$ & $\mathrm{R}$ & $\mathrm{R}$ & $\mathrm{R}$ & $\mathrm{R}$ & $\mathrm{R}$ & $\mathrm{R}$ & $\mathrm{R}$ & \\
\hline & & \multicolumn{2}{|l|}{ THURSDAY } & 1 & 1 & 1 & 1 & 1 & 1 & 1 & 1 & \\
\hline & & \multicolumn{2}{|l|}{ FRIDAY } & 1 & 1 & 1 & 1 & 1 & 1 & 1 & 1 & \\
\hline & & \multicolumn{2}{|l|}{ SATURDAY } & 1 & 1 & 1 & 1 & 1 & 1 & 1 & 1 & \\
\hline & & \multicolumn{2}{|l|}{ SUNDAY } & $\mathrm{R}$ & $\mathrm{R}$ & $\mathrm{R}$ & $\mathrm{R}$ & $\mathrm{R}$ & $\mathrm{R}$ & $\mathrm{R}$ & $\mathrm{R}$ & \\
\hline \multirow{9}{*}{7} & \multirow{9}{*}{  } & \multirow{3}{*}{ STRENGTH } & Maximum Strength & 5 & 15 & 20 & - & - & - & - & & \\
\hline & & & Strength Endurance & 25 & 5 & - & - & - & - & - & & \\
\hline & & & Explosive Power & - & - & 5 & 20 & 20 & 20 & 20 & 10 & \\
\hline & & \multirow{2}{*}{ SPEED } & Maximum Speed & - & - & 5 & 20 & 20 & 10 & 10 & 10 & \\
\hline & & & Speed Endurance & - & 10 & 20 & - & - & - & - & - & \\
\hline & & \multicolumn{2}{|c|}{ ENDURANCE } & 50 & 30 & - & - & - & - & - & - & \\
\hline & & \multicolumn{2}{|c|}{ COORDINATION } & 5 & 5 & 5 & 5 & 5 & 5 & 5 & 5 & \\
\hline & & MOBILITY-FL & EXIBILITY & 15 & 15 & 15 & 15 & 15 & 15 & 15 & 15 & \\
\hline & & TECHNQUE & TACTIC & - & 20 & 30 & 40 & 40 & 50 & 50 & 60 & \\
\hline
\end{tabular}

R: Rest; T: Test

Table 2. Physical features of the taekwondo athletes.

\begin{tabular}{lllllll}
\hline & $\begin{array}{l}\text { Male } \\
\text { Parameters }\end{array}$ & & & \multicolumn{3}{l}{ Female } \\
(n= 12) & & & & \\
& Min & Max & Mean \pm Sd & Min & Max & Mean \pm Sd \\
\hline Age (year) & 19.00 & 23.00 & $20.33 \pm 1.41$ & 17.00 & 23.00 & $20.33 \pm 1.96$ \\
Exercise age (year) & 7.00 & 14.00 & $9.55 \pm 2.78$ & 6.00 & 13.00 & $8.83 \pm 1.94$ \\
Height (cm) & 176.00 & 188.00 & $181.77 \pm 3.99$ & 157.00 & 178.00 & $169.50 \pm 5.94$ \\
Weight (kg) & 63.00 & 82.00 & $69.33 \pm 5.91$ & 48.00 & 69.00 & $60.16 \pm 7.87$ \\
BMI (kg/m2) & 20.09 & 23.20 & $20.94 \pm 1.00$ & 17.63 & 24.45 & $20.91 \pm 2.29$ \\
\hline
\end{tabular}

$(\mathrm{z}=-2,984), \operatorname{MPV}(\mathrm{z}=-3,062)$ and $\operatorname{PCT}(\mathrm{z}=-2,283)$ parameters $(p<0.05)$. However, there was statistically no significant difference $(p>0.05)$ for the other parameters.

\section{Discussion}

In this study, the effects of preparation period exercises, which were applied for eight weeks to elite level taekwondo athletes, on the hematological parameters were examined.

When we examined the leukocyte and subparameters of the female taekwondo athletes, we determined increases in WBC, GRAN, GRAN \% and
LYM parameters compared to those taken before the preparation period. Additionally, we determined decreases in the other parameters, however, they were statistically not significant. As per the males, we detected decreases in GRAN \% and LYM \% parameters, and increases in all other parameters, however, they were statistically not significant, either. In a similar study conducted on taekwondo athletes, it was stated that a 4 -week camp period exercise increased the WBC values of the athletes; however, it was statistically not significant [15]. In two different studies conducted on football athletes examining the effect of acute exercise and 10-day game program on 
Table 3. Average values of hematological parameters of male taekwondo athletes and the results of Wilcoxon Signed Rank test. $(p<0.05)$

\begin{tabular}{|c|c|c|c|c|c|c|c|c|}
\hline \multirow{3}{*}{ Parameters } & \multirow{2}{*}{\multicolumn{2}{|c|}{$\begin{array}{l}\text { Pre-test } \\
(n=9)\end{array}$}} & \multirow{2}{*}{\multicolumn{3}{|c|}{$\begin{array}{l}\text { Post-test } \\
(n=9)\end{array}$}} & \multirow[b]{3}{*}{ Mean \pm Sd } & \multirow[b]{3}{*}{$\mathbf{z}$} & \multirow[b]{3}{*}{$p$} \\
\hline & & & & & & & & \\
\hline & Min & Max & Mean \pm Sd & Min & Max & & & \\
\hline \multicolumn{9}{|c|}{ Leukocyte sub-groups } \\
\hline$W B C\left(10^{\wedge} 3 / \mu L\right)$ & 5.10 & 9.60 & $6.18 \pm 1.38$ & 4.90 & 8.00 & $6.76 \pm 1.12$ & -1.304 & 0.192 \\
\hline $\operatorname{GRAN}\left(10^{\wedge} 3 / \mu \mathrm{L}\right)$ & 2.30 & 6.20 & $3.44 \pm 1.13$ & 2.00 & 5.20 & $3.57 \pm 0.98$ & -1.007 & 0.314 \\
\hline GRAN (\%) & 42.70 & 64.30 & $54.74 \pm 6.06$ & 25.30 & 70.00 & $54.35 \pm 12.31$ & -0.533 & 0.594 \\
\hline $\operatorname{LYM}\left(10^{\wedge} 3 / \mu \mathrm{L}\right)$ & 1.80 & 2.60 & $2.10 \pm 0.31$ & 1.40 & 2.70 & $2.11 \pm 0.40$ & -0.141 & 0.888 \\
\hline LYM (\%) & 25.90 & 47.50 & $34.55 \pm 6.32$ & 23.40 & 38.20 & $31.95 \pm 4.30$ & -0.653 & 0.514 \\
\hline $\operatorname{MID}\left(10^{\wedge} 3 / \mu \mathrm{L}\right)$ & 0.50 & 0.90 & $0.65 \pm 0.13$ & 0.50 & 3.30 & $0.91 \pm 0.90$ & -0.542 & 0.588 \\
\hline MID (\%) & 9.20 & 13.00 & $10.70 \pm 1.09$ & 6.60 & 40.90 & $13.70 \pm 10.37$ & -0.542 & 0.953 \\
\hline \multicolumn{9}{|c|}{ Erythrocyte sub-groups } \\
\hline $\operatorname{RBC}\left(10^{\wedge} 6 / \mu \mathrm{L}\right)$ & 4.82 & 6.16 & $5.26 \pm 0.45$ & 4.91 & 5.93 & $5.37 \pm 0.31$ & -1.007 & 0.314 \\
\hline $\mathrm{HGB}(\mathrm{g} / \mathrm{dL})$ & 11.40 & 16.60 & $15.07 \pm 1.54$ & 10.60 & 16.50 & $15.20 \pm 1.81$ & -0.595 & 0.552 \\
\hline HCT (\%) & 35.70 & 51.00 & $45.88 \pm 4.39$ & 33.40 & 47.50 & $44.34 \pm 4.41$ & -1.304 & 0.192 \\
\hline $\mathrm{MCV}(\mathrm{fL})$ & 62.20 & 98.00 & $87.68 \pm 10.99$ & 58.40 & 92.00 & $82.78 \pm 10.12$ & -2.675 & 0.007 \\
\hline $\mathrm{MCH}(p g)$ & 19.90 & 32.60 & $28.82 \pm 3.78$ & 18.50 & 33.20 & $28.76 \pm 4.33$ & -0.771 & 0.440 \\
\hline $\mathrm{MCHC}(\mathrm{g} / \mathrm{dL})$ & 31.90 & 33.40 & $32.83 \pm 0.52$ & 31.70 & 38.20 & $34.42 \pm 1.71$ & -2.549 & 0.011 \\
\hline RDWC (\%) & 12.90 & 19.30 & $14.25 \pm 1.94$ & 12.80 & 23.70 & $15.53 \pm 3.63$ & -0.533 & 0.594 \\
\hline \multicolumn{9}{|c|}{ Thrombocyte sub-groups } \\
\hline $\operatorname{PLT}\left(10^{\wedge} 3 / \mu L\right)$ & 196.00 & 321.00 & $254.22 \pm 43.64$ & 179.00 & 314.00 & $249.66 \pm 41.14$ & $-0,296$ & 0.767 \\
\hline MPV (fL) & 8.10 & 11.70 & $10.21 \pm 1.01$ & 8.00 & 10.50 & $9.72 \pm 0.72$ & $-2,092$ & 0.036 \\
\hline $\begin{array}{l}\text { PCT (\%) } \\
\text { PDW (\%) }\end{array}$ & $\begin{array}{l}0.21 \\
15.80\end{array}$ & $\begin{array}{l}0.33 \\
17.10\end{array}$ & $\begin{array}{l}0.25 \pm 0.03 \\
16.46 \pm 0.47\end{array}$ & $\begin{array}{l}0.15 \\
15.70 \\
\end{array}$ & $\begin{array}{l}0.27 \\
17.10 \\
\end{array}$ & $\begin{array}{l}0.21 \pm 0.03 \\
16.24 \pm 0.51\end{array}$ & $\begin{array}{l}-2,075 \\
-1,187 \\
\end{array}$ & $\begin{array}{l}0.038 \\
0.235 \\
\end{array}$ \\
\hline
\end{tabular}

Table 4. Mean values of hematological parameters of female taekwondo athletes and the results of Wilcoxon Signed Rank Test. ( ${ }^{*} p<0.05$.)

\begin{tabular}{|c|c|c|c|c|c|c|c|c|}
\hline \multirow[t]{2}{*}{ Parameters } & \multicolumn{3}{|l|}{$\begin{array}{l}\text { Pre-test } \\
(n=12)\end{array}$} & \multicolumn{5}{|c|}{$\begin{array}{l}\text { Post-test } \\
(n=12)\end{array}$} \\
\hline & Min & Max & Mean \pm Sd & Min & Max & Mean \pm Sd & $\mathbf{z}$ & $p$ \\
\hline \multicolumn{9}{|c|}{ Leukocyte sub-groups } \\
\hline $\mathrm{WBC}\left(10^{\wedge} 3 / \mu \mathrm{L}\right)$ & 4.00 & 9.90 & $7.06 \pm 1.90$ & 5.70 & 13.90 & $7.90 \pm 2.45$ & -1.413 & 0.158 \\
\hline $\operatorname{GRAN}\left(10^{\wedge} 3 / \mu \mathrm{L}\right)$ & 1.80 & 7.20 & $4.65 \pm 1.83$ & 3.10 & 9.60 & $5.32 \pm 2.00$ & -1.531 & 0.126 \\
\hline GRAN (\%) & 45.30 & 86.10 & $63.78 \pm 11.56$ & 51.90 & 75.90 & $66.08 \pm 7.94$ & -0.941 & 0.347 \\
\hline $\operatorname{LYM}\left(10^{\wedge} 3 / \mu \mathrm{L}\right)$ & 0.70 & 2.60 & $1.76 \pm 0.45$ & 1.20 & 3.30 & $1.92 \pm 0.55$ & -0.945 & 0.345 \\
\hline LYM (\%) & 9.10 & 41.60 & $26.73 \pm 9.65$ & 17.60 & 39.50 & $25.61 \pm 7.38$ & -0.628 & 0.530 \\
\hline $\operatorname{MID}\left(10^{\wedge} 3 / \mu \mathrm{L}\right)$ & 0.40 & 1.10 & $0.66 \pm 0.21$ & 0.50 & 1.00 & $0.64 \pm 0.17$ & -0.240 & 0.810 \\
\hline MID (\%) & 4.80 & 13.10 & $9.48 \pm 2.58$ & 6.50 & 9.90 & $8.30 \pm 0.98$ & -1.511 & 0.131 \\
\hline \multicolumn{9}{|c|}{ Erythrocyte sub-groups } \\
\hline $\mathrm{RBC}\left(10^{\wedge} 6 / \mu \mathrm{L}\right)$ & 4.04 & 5.07 & $4.52 \pm 0.27$ & 4.23 & 5.23 & $4.59 \pm 0.24$ & -1.694 & 0.090 \\
\hline HGB (g/dL) & 11.80 & 14.50 & $13.10 \pm 0.69$ & 11.70 & 14.70 & $13.00 \pm 0.89$ & -0.357 & 0.721 \\
\hline HCT (\%) & 35.70 & 44.50 & $39.70 \pm 2.12$ & 34.60 & 42.70 & $38.38 \pm 2.27$ & -2.943 & 0.003 \\
\hline $\mathrm{MCV}(\mathrm{fL})$ & 78.90 & 99.00 & $87.90 \pm 5.80$ & 75.00 & 90.20 & $83.69 \pm 4.82$ & -2.981 & 0.003 \\
\hline $\mathrm{MCH}(p g)$ & 26.00 & 31.70 & $28.99 \pm 1.87$ & 25.30 & 30.20 & $28.35 \pm 1.72$ & -2.119 & 0.034 \\
\hline $\mathrm{MCHC}(\mathrm{g} / \mathrm{dL})$ & 32.00 & 33.90 & $33.00 \pm 0.60$ & 33.10 & 34.50 & $33.85 \pm 0.50$ & -2.984 & 0.003 \\
\hline RDWC (\%) & 12.80 & 20.40 & $14.51 \pm 2.07$ & 12.50 & 16.30 & $14.12 \pm 1.37$ & -0.353 & 0.724 \\
\hline \multicolumn{9}{|c|}{ Thrombocyte sub-groups } \\
\hline $\operatorname{PLT}\left(10^{\wedge} 3 / \mu \mathrm{L}\right)$ & 152.00 & 343.00 & $244.41 \pm 54.40$ & 179.00 & 307.00 & $248.75 \pm 48.35$ & -0.510 & 0.610 \\
\hline MPV (fL) & 9.20 & 13.30 & $11.29 \pm 1.04$ & 8.60 & 11.20 & $9.96 \pm 0.74$ & -3.062 & 0.002 \\
\hline $\begin{array}{l}\text { PCT (\%) } \\
\text { PDW (\%) }\end{array}$ & $\begin{array}{l}0.16 \\
15.30 \\
\end{array}$ & $\begin{array}{l}0.39 \\
17.50 \\
\end{array}$ & $\begin{array}{l}0.27 \pm 0.06 \\
16.36 \pm 0.65\end{array}$ & $\begin{array}{l}0.16 \\
15.20 \\
\end{array}$ & $\begin{array}{l}0.31 \\
17.50 \\
\end{array}$ & $\begin{array}{l}0.24 \pm 0.04 \\
16.29 \pm 0.77\end{array}$ & $\begin{array}{l}-2.283 \\
-0.306 \\
\end{array}$ & $\begin{array}{l}0.022 \\
0.759 \\
\end{array}$ \\
\hline
\end{tabular}


the hematological parameters, it was reported that there were increases in the leukocyte values, however, they were statistically not significant $[11,16]$. In another study conducted on female basketball athletes aiming to determine the relations between the blood parameters and some performance values from upper extremity, WBC values were reported as $6.8510^{\wedge} 3 / \mu \mathrm{L}$ [17]. In a different study conducted on basketball athletes, it was reported that a 12-day intense competition period caused an increase in the WBC parameter, however, it was statistically not significant [3]. It can be stated that previous studies support the findings of this study. However, opposing to the findings of this study, there are studies which state $[12,18]$ that exercises conducted on sedentary individuals and in different sport branches caused decreases in the leukocyte level. In addition to these, there are also studies reporting that it caused statistically significant increases $[6,19,20]$. These post-exercise increases at the leukocyte levels are reported to be originated from de-margination, which, after the increasing blood stream with exercise, is defined as joining of the leukocytes that stick to the walls of the veins to the blood stream $[21,22]$. Moreover, it is known that high intensity exercises create a heavy stress over the organism, and as a reaction to that, the count of the leukocytes could significantly increase together with some hormonal changes. Accordingly, as Patlar (2010) reported, particularly with the increasing pressure after the strength exercises, the cortisol level increases, this brings an increase in the level of the leukocyte, as well [23]. However, that the differences in the leukocyte and sub-group parameter values were not statistically significant in this research study might be an indicator of the adaptation of the athletes against pressure in the organism caused by the exercise.

When we examined the erythrocyte and sub-parameters, compared to the values taken before preparation period, we observed statistically significant differences. These differences were concerning the $\mathrm{HCT}, \mathrm{MCV}, \mathrm{MCH}$ and $\mathrm{MCHC}$ parameters of the female taekwondo athletes, and concerning the $\mathrm{MCV}$ and $\mathrm{MCHC}$ parameters of the male taekwondo athletes. However, we determined that the values for the other sub-parameters taken before and after the preparation period were statistically nonsignificant. In a research study conducted on national and international level 13 male $800 \mathrm{~m}$ runners, comparing the summer and winter competition periods, it was determined that there were decreases for the RBC values and also statistically significant decreases for the HCT values [2]. It was reported that short term intensive basketball competition caused a statistically significant decrease for the HCT parameters of the athletes, while causing a statistically non-significant decrease for RBC and HGB parameters [3]. Moreover, in another study conducted on long distance runners $(n=31)$, it was stated that there were statistically significant decreases for the RBC and HGB values compared to the pre-competition values [24]. In another study conducted on the maximal strength development of elite level female weightlifting athletes, it was reported that there were decreases for erythrocyte and sub-parameters [4]. Although the accessible literature findings support the findings of this study, İbiş et al. (2010) reported that there were significant increases for the HBG and HCT values after an anaerobic exercise [21]. On the other hand, Mashiko et al. (2004) stated that a 20-day camp period applied to the rugby athletes did not cause any statistically significant difference for HCT values [25]. In another study conducted on taekwondo athletes, there were statistically significant increases for the RBC values, and non-significant increases for HGB and HCT values [15]. Although it was reported that these increases depended on the plasma losses caused by the exercise, we evaluated that the motive behind the decrease in the erythrocyte values might be the intravenous hemolysis caused by the trauma due to the intense exercises in this study.

When we examined the thrombocyte and its subparameters, compared to the values obtained before the preparation period, we observed that there were decreases in all parameters of both male and female taekwondo athletes, except for the PLT value of the female taekwondo athletes. As far as the accessible literature findings, although there are many research studies $[12,15$, $16,21,24,26-28]$ reporting that both acute and chronic exercises cause increases in the values of thrombocyte and its sub-parameters, there are also studies $[2,3,18]$ reporting that they cause a decrease. Increases obtained in the PLT levels are attributed to both exercise-contingent hemoconcentration and sympathetic nervous system activation, which is caused by stress-creating factors and the organism under pressure. We evaluate that, although statistically not significant, the increase in the PLT level in this study is caused by fresh thrombocyte secretion from either spleen, bone marrow, or other reservoirs. It is thought that the effects of exercise on the count of thrombocyte is questionable, therefore, a more in-depth research study is needed.

\section{Conclusions}

It can be accepted as a strength of the study that the research group of this study is comprised of male and female athletes with participation experiences in national or international level competitions. Additionally, some findings were obtained as a result of the exercises conducted during the preparation period with the full participation. However, in order for the results to be more significant, we evaluated that further studies should be conducted with a higher number of participants and with different load intensities. In this study, which was conducted on elite level taekwondo athletes, leukocyte, erythrocyte, thrombocyte, and their sub-parameters, totally 18 parameters were examined. There were statistically significant differences for 6 parameters of the female taekwondo athletes and for 4 parameters of the male taekwondo athletes. Although we observed increases and decreases in the other parameters, we determined that these differences were statistically not significant.

As a result, we can state that the preparation period exercises, which were conducted for 8 weeks, caused 
increases or decreases in the hematological parameters of male and female taekwondo athletes. However, this effect was limited and it did not cause a significant change. We attribute it to that the athletes in the research group are elite level competitor athletes and that they developed an adaptation ability to the stress caused by the chronic exercise.

\section{Acknowledgments}

The authors sincerely thank the subjects, who participated in this study and contributed to the realization of this project. This research received no funding.

\section{Conflicts of interest}

The authors declare no conflict of interest.

\section{References}

1. Hazar S, Koc H. The analysis of the heart structure and heart functions of the wrestler who were at the Turkish national team level by electrocardiograph method. Gazi BESBD.2003; 8: 3-14.

2. Bachero-Mena B, Pareja-Blanco F, González-Badillo JJ. Enhanced strength and sprint levels, and changes in blood parameters during a complete athletics season in $800 \mathrm{~m}$ high-level athletes. Frontiers in Physiology. 2017;8: 1- 10. https://doi.org/10.3389/fphys.2017.00637

3. Gencer YG, Coskun F, Sarikaya M, Kaplan S. Investigation on the effects of 12 days intensive competition on some blood parameters of basketball athletes. $J$. of Educ. and Training Studies. 2018; 6(4): 79- 83. https://doi.org/10.11114/jets.v6i4.3011

4. Erdağı K, Yüksel MF, Sevindi T. The effects of maximal power training on hematologic parameters of female weightlifters. The Journal of Turkish Sport Sci. 2018; 1(1): 41-49.

5. Lorenz DS, Reiman MP, Lehecka BJ, Naylor A. What Performance characteristics Determine Elite Versus Nonelite Athletes in the Same Sport? Sports Health: A Multidisciplinary Approach, 2013;5:542-7.

6. Heidari N, Dortaj E, Karimi M, Karami S, Kordi N. The effects of acute high intensity interval exercise of judo on blood rheology factors. Turk. J. Kinesiol.2016;2: 6-10.

7. Ajmani RS, Fleg JL, Demehin AA, Wright JG, O'Connor F, Heim JM, Tarien E, Rifkind JM. Oxidative stress and hemorheological changes induced by acute treadmill exercise. Clin. Hemorheol. Microcirc. 2003;28: 29-40.

8. Wardyn GG, Rennard SI, Brusnahan SK, McGuire TR, Carlson ML, Smith LM, McGranaghan S, Sharp JG. Effects of exercise on hematological parameters, circulating side population cells, and cytokines. Exp. Hematol. 2008;36: 216- 223. https://doi.org/10.1016/j.exphem.2007.10.003

9. Wu HJ, Chen KT, Shee BW, Chang HC, Huang YJ, Yang RS. Effectsof24hultra-marathononbiochemicalandhematological parameters. World J. Gastroenterol. 2004;10: 2711- 2714. https://doi.org/10.3748/wjg.v10.i18.2711

10. Mairbäurl H. Red blood cells in sports: effects of exercise and training on oxygen supply by red blood cells. Frontiers in Physiology.2013; 4 https://doi.org/10.3389/fphys.2013.00332

11.Çelik A, Varol R, Onat T, Dağdelen Y, Tugay F. The effects of acute exercise on the parameters of antioxidant system in football athletes. Ankara Unv. Faculty of Sport Sci. SPORMETRE J. of Physical Educ. and Sports Sci. 2007; 5(4): 167-172.

12.Saddam A, Ali B, Abdelatif H. Analysis of the evolution of some hematological parameters during the first preparatory period on young Algerian soccer athletes (U17). European $J$. of Physical Educ. and Sport Sci. 2017; 3(10): 128-134.

13.Brun JF. Exercise hemorheology as a three acts play with metabolic actors: is it of clinical relevance? Clin. Hemorheol. Microcirc. 2002;26: 155-174.

14.Haas TL,LloydPG, Yang HT, Terjung RL.Exercise training and peripheralarterialdisease.Compr.Physiol.2012;2:2933-3017. https://doi.org/10.1002/cphy.c110065

15.Cakmakçı E. Effects of camp term on some hematological parameters in male taekwondoers. J. Phys. Educ. Sports Sci. 2009; 3(1): 21-29.

16.Çınar V, Cengiz Ş, Pala R, Dündar A. Effect of football practices on certain blood values of athletes. Advances in Environmental Biology. 2013;7: 924-927.

17.Soslu R, Eyuboğlu E, Cuvalcıoğlu İC, Özkan A. Effects of blood parameters and some morphological variables on some upper extremity physical fitness performance in female basketball athletes. International Journal of Cultural and Social Studies. 2017;3: 347-353.

18.Demiriz M, Erdemir İ, Kayhan RF. Effects of anaerobic interval training with different rest interval on aerobic capacity, anaerobic threshold and blood parameters. Int. J. of Sport, Exer. and Train. Sci. 2015;1(1): 1- 8. https://doi.org/10.18826/useeabd.233120

19.Erdemir I. The comparison of blood parameters between morning and evening exercise. European Journal of Experimental Biology. 2013; 3(1): 559-563.

20.Suzuki K, Nakaji S, Yamada M, Liu Q, Kurakake S, Okamura N, Kumae T, Umeda T, Sugawara K. Impact of a competitive marathon race on systemic cytokine and neutrophil responses. Medicine and Science in Sports and Exercise. 2003; 35(2): 348- 355. https://doi.org/10.1249/01.MSS.0000048861.57899.04

21.İbis S, Hazar S, Gökdemir K. Acute effect of hematological parameters on aerobic and anaerobic exercise. International Journal of Human Sciences. 2010;7(1): 70-82.

22.Sodique NO, Enyikwola O, Ekanem AU. Exercise-induced leucocytosis in some healthy adult Nigerians. African Journal of Biomedical Research. 2000; 3(2): 85-88.

23.Patlar S. Effects of acute and 4 week submaximal exercise on leukocyte and leukocyte subgroups. Isokinetics and Exercise Science. 2010;18(3): 145- 148. https://doi.org/10.3233/IES-2010-0373

24.Lippi G, Salvagno GL, Danese E, Tarperi C, Guidi GC, Schena F. Variation of Red Blood Cell Distribution Width and Mean Platelet Volume after Moderate Endurance Exercise. Advances in Hematologyб 2014;2014:1-4. https://doi.org/10.1155/2014/192173

25.Mashiko T, Umeda T, Nakaji S, Sugawara K. Effects of exercise on the physical condition of college rugby athletes during summer training camp. Br J Sports Med. 2004; 38(2): 186- 90. https://doi.org/10.1136/bjsm.2002.004333

26.Belviranli M, Okudan N, Kabak B. The effects of acute high-intensity interval training on hematological parameters in sedentary subjects. Medical Sciences. 2017; 5(3): 15. https://doi.org/10.3390/medsci5030015

27. Yapıc1 A, Dündar U. Influence of shuttle run tests on hemorheological parameters. Turkish Jounal of Sports Medicine. 2006:41: 87-94.

28.Kilim SR, Lakshmi PVV. A study on affect of severity of exercise on platelet function. Journal of Evolution of Medical and Dental Sciences. 2015; 4(58): 10027- 10032. https://doi.org/10.14260/jemds/2015/1451 


\section{Information about the authors:}

Boyalı E.; Associate Professor; http://orcid.org/0000-0002-6559-7640; eboyali@selcuk.edu.tr; Faculty of Sports Science, Selçuk University; Konya, 42130, Turkey.

Sevindi T.; Associate Professor; http://orcid.org/0000-0001-7007-170X; tariksevindi@gmail.com; Faculty of Sports Science, Aksaray University; Aksaray 68100, Turkey.

Yüksel M.F.; Assistant Professor; http://orcid.org/0000-0001-6481-5098; yukselmehmetfatih@gmail.com; Faculty of Education, Necmettin Erbakan University; Konya 42090, Turkey.ю

Demir H. (Corresponding Author); Associate Professor; http://orcid.org/0000-0001-9496-8992; hayri.demirsbf@gmail.com; Faculty of Sports Science, Selçuk University; Konya, 42130, Turkey.;

\section{Cite this article as:}

Boyalı E, Sevindi T, Yüksel MF, Demir H. The effects of preparation period exercises on the hematological parameters of the taekwondo athletes. Physical education of students, 2019;23(1):9-15.

https://doi.org/10.15561/20755279.2019.0102

The electronic version of this article is the complete one and can be found online at: https://sportedu.org.ua/index.php/PES/issue/archive

This is an Open Access article distributed under the terms of the Creative Commons Attribution License, which permits unrestricted use, distribution, and reproduction in any medium, provided the original work is properly cited http://creativecommons.org/licenses/by/4.0/deed.en

Received: 18.12 .2018

Accepted: 16.01.2019; Published: 28.02.2019 